\title{
The Analysis of Pricing Power of Preponderant Metal Mineral Resources under the Perspective of Intergenerational Equity and Social Preferences: An Analytical Framework Based on Cournot Equilibrium Model
}

\author{
Meirui Zhong, ${ }^{1,2}$ Anqi Zeng, ${ }^{1}$ Jianbai Huang, ${ }^{1,2}$ and Jinyu Chen ${ }^{1,2}$ \\ ${ }^{1}$ School of Business, Central South University, Changsha 410083, China \\ ${ }^{2}$ Institute of Metal Resources Strategy, Changsha 410083, China \\ Correspondence should be addressed to Meirui Zhong; zmr726@163.com
}

Received 2 April 2014; Accepted 27 May 2014; Published 17 June 2014

Academic Editor: Fenghua Wen

Copyright (C) 2014 Meirui Zhong et al. This is an open access article distributed under the Creative Commons Attribution License, which permits unrestricted use, distribution, and reproduction in any medium, provided the original work is properly cited.

\begin{abstract}
This paper combines intergenerational equity equilibrium and social preferences equilibrium with Cournot equilibrium solving the technological problem of intergenerational equity and strategic value compensation confirmation, achieving the effective combination between sustainable development concept and value evaluation, thinking and expanding the theoretical framework for the lack of pricing power of mineral resources. The conclusion of the theoretical model and the numerical simulation shows that intergenerational equity equilibrium and social preferences equilibrium enhance international trade market power of preponderant metal mineral resources owing to the production of intergenerational equity compensation value and strategic value. However, the impact exerted on Cournot market power by social preferences is inconsistent: that is, changes of altruistic Cournot equilibrium and reciprocal inequity Cournot equilibrium are consistent, while inequity aversion Cournot equilibrium has the characteristic of loss aversion, namely, under the consideration of inequity aversion Cournot competition, Counot-Nash equilibrium transforms monotonically with sympathy and jealousy of inequity aversion.
\end{abstract}

\section{Introduction}

Pricing power is the ability where related market participants manipulate market equilibrium price away from international trade fair price in its favor by market forces. In recent years, the sustainable growth of China's economy is the important engine driving the growth of the world economy and the increasing demand of staple commodities, such as metal mineral products. The influence exerted on global economy by China is called "China Factor" internationally. However the so-called "China Factor" does not bring corresponding pricing power to China; instead, metal mineral resources international trade price of our country is stuck in the dilemma. The export price of preponderant metal mineral resources, such as rare earth, lithium, and indium, experienced a long-term slump, which not only cause economic loss but also leave the burden of energy consumption and environmental protection to China, so that it is equivalent to providing hidden subsidies at the cost of ecological environment destruction and mineral resources rapid depletion. Therefore, the reports of the seventeenth and eighteenth congress of the CPC put forward continuously $[1,2]$, "deepen the resource products price and tax reform, establish compensated use system and eco-compensation system reflected the market supply and demand, resource scarcity and intergenerational compensation." Although intergenerational compensation is stressed in reports, externalities resulting from productive process of metal mineral resources development and utilization are not included in metal mineral resources value system as the form of cost. The proportion of calculated mineral resources compensation fees to sales revenue is approximately $1.18 \%$, far lower than the level of $2 \%-8 \%$ of 
foreign premium. The premium rate and compensation fees of rare earth in China are far lower than Australia, the USA, South Africa, and Vietnam. The technological problem of cost confirmation and measurement and serious distortion of tax policy prevent mineral resource development and utilization from reasonable value compensations, causing unfairness in international trade fair price, and above all that is the important reason why China loses pricing power.

Considering that the international trade price of metal mineral resources is also affected by factors such as supply and demand and speculation (expectation), the complete value compensation system including marginal cost of production, marginal user cost, and external cost (ecological value and intergenerational compensation value) is only the static reason to explain pricing power deficiency. Especially to preponderant metal mineral resources, such as rare earth, lithium, and indium, their international trade price is mainly dependent on mutual bargaining, which is affected by psychological preferences of players and thus produce strategic value. While ignoring objectivity of strategic value in policy suggestion making is another reason accounted for pricing power deficiency. Because according to social preference equilibrium analysis, unless the international trade price is fair and it achieves equilibrium among players, it is difficult for metal mineral resources development and utilization to achieve success. Using traditional game equilibrium evaluation method can reflect the economic value connotation accurately; however, a certain mineral resource development and utilization are accepted only when players approve of economic value and ecological value and the fairness of metal mineral resources development compensation price psychologically. So fairness correction on metal mineral resources development compensation basic value is necessary in reality.

Classical literatures discussing pricing fairness from a perspective of mineral resources development value compensation include "Hotelling Rule" [3], raised by Hotelling, namely, mineral resources, as a kind of asset, need depreciation, so the depletion of mineral resources could be compensated by taxation; "Hartwick Rule" [4] raised by Hartwick, pointed out that if mining rent of nonrenewable resources saved as productive investment, the investment across generations is equal to achieve sustainability of economic growth, when the investment is greater than resources value extracted by resources owners. Serafy [5] adds environmental losses to the research work of national income accounting system and raises user cost approach to calculate real income and the value depletion of nonrenewable resources, which is a new national income accounting method in nonrenewable resources field; later, Serafy [6] makes improvement in this method. This approach lays the foundation of depletion cost pricing of nonrenewable mineral resource; therefore, it is used by many scholars to measure user cost of various mineral resources and analyze the reasonability of premium system and resources tax and fee policy, such as Adelman [7] calculates user cost of some large oil and gas companies by user cost approach and compares with premium; Young and Seroa Da Motta [8] count user cost of major minerals in Brazil by this method; Blignaut and Hassan [9] estimate user costs of underground mineral resources in South Africa; Lin et al. [10] discover the inadaptability of user cost approach in coal resources of China; thus, he uses the modified approach to estimate real cost of coal resources and builds CGE model to determine detailed tax rates; G. P. Li and H. W. Li [11] correct the defects of user cost method and use it to calculate user cost of oil and gas in the United States; Zeng and Li [12] use fixed user cost approach to count user cost of coal, oil, and natural gas in China during 19852010, after taking depletion in resource development and the effects of inflation into account. These researches above solve problems of metal mineral resources compensation scarcity value but ignore environmental costs and intergenerational equity value and lack explanation for influences exerted on market and international trade price by intergenerational equity compensation value. On the other hand, many scholars do researches on pricing power, such as Fattouh [13] who suggests that pricing power is the ability for manufacturers directly affecting the other market participants and market variables, such as price and sales, so market pricing power is a kind of price bonus ability; Kaufmann [14] argues that pricing power is the technical strength which is associated with market power to some extent, that is, enterprises could obtain monopoly pricing power in the market by its unique technology or patents, thus gaining excess profits. Rubinstein [15] explains staple commodity pricing mechanism by using the bargaining model of complete information dynamic game and deems that pricing power advantage between buyers and sellers mainly depends on bargaining patience of two sides when information is complete. Wen et al. [16-19] hold that influences on market structure carried by risk preference and risk premium should be taken into account in bargaining model, for risk preference characteristics will affect pricing power by affecting market power. Some researches specific to rare earth pricing power following the above trend are carried out, such as Zhang [20] who thinks that the rare earth market belongs to a typical oligopoly market, so oligopolistic enterprise must fully consider impacts from competitors before taking any action, which proves game behavior of oligopolists on both sides existed in the pricing process of rare earth; Wang and Zhang [21] analyze the potential impact on China's rare earth export pricing power by the increase of resource tax; $\mathrm{Wu}$ and Jiang [22] hold that the formation of pricing power is a result of comprehensive shaping process involving many factors, such as, industry, enterprise, government, and foreign aspects, which all are passed on to the market power.

The analysis above is static interpretation of pricing power, without considering the influence on market power by psychological preferences. Based on remarkable discovery of game experiment, behavioral economics expand and correct the traditional economic theory through integrating behavioral and psychological preferences into it, especially blending social preference in game and decision-making theories. As an effective analytical tool for economic subject of cooperative game, it brings profound impact on the raise of fairness preference and application in motivation theory and industrial organizational theory, such as Rabin [23] who starts original research toward fair game equilibrium and 
builds a reciprocal fairness equilibrium game model based on the framework of psychological game raised by Geanakoplos, Pearce, and Stacchetti. This model depicts reciprocal fairness motivation of players as motivation fairness utility function and then discovers a new equilibrium, that is, fairness equilibrium, which meets the Pareto optimality with cooperative equilibrium and provides a reasonable explanation for cooperative results. However, Rabin's model is difficult to predict accurately because it only aimed at games with standard form, not for dynamic game with continuous strategy structure. Dufwenberg and Kirchsteiger [24] improve Rabin's model through expanding it to a dynamic environment with continuous strategy structure, thus obtaining a more extensive application. According to fairness preference based on distribution results revealed by game experiments, Fehr and Schmidt [25] and Bolton and Ockenfels [26] develop inequity aversion model based on distribution results. It could be deduced from research achievements of reciprocal equity equilibrium theory that metal mineral resources development and compensation value are dependent on not only material benefits brought by resource development, but also psychological effect contained by reciprocal fairness belief, if only a reciprocal fairness belief of related subjects is given. Therefore, a correlation consideration is established between reciprocal equity equilibrium analysis and metal mineral resources development and compensation evaluation, consequently revealing the mechanism of pricing power affected by psychological preferences. The breakthrough of theory model in psychological preferences utility assumes the analysis of pricing power affected by market power ignoring psychological preferences, which will affect the bargaining strategy of players, change the market power and influence supply and demand prices of mineral products. For instance, Zhong et al. [27] estimate intergenerational compensation of preponderant high-tech mental mineral resources affected by altruism preference and reciprocal fairness equilibrium with Stackelberg model and points out that the development and utilization of compensation value system should include intergenerational compensation and strategic value besides economic value and ecological value.

Based on the researches above, this paper analyzes market structure of preponderant mental mineral resources such as tungsten, molybdenum, tin, antimony, and rare earth and integrates social preference into Cournot production decision model to analyze the impact exerted on market structure, production decision of developers, price, and profits by social profits, thus discovering the existence of new equilibrium, intergenerational compensation, and strategic value, which clears the agreement pricing mechanism of the metal mineral resources and reveals the pricing power routes affected by intergenerational equity and social preferences.

\section{The Function Routes of Intergenerational Equity to Preponderant Metal Mineral Resources Pricing Power}

2.1. Cournot Market Structure Analysis of Preponderant Metal Mineral Resources. Cournot, French mathematical economist, first outlined his theory of duopoly market in 1838. In this situation, there exist two enterprises supplying homogeneous products in the market. Each enterprise could choose optimal production to maximize profits by observing others production. He then discovered that a stable equilibrium occurs where each enterprise chooses the production as their rival expected. So the model has a series of strict assumptions: the market is only dominated by two rational suppliers aiming at profit maximization; Oligarch production competition is strategic for supposing each other's output expectation function and price determined by market production; Oligarch determines their own production after prediction and assumes the output of their rival is fixed; the cost of production of oligarchs is zero and marginal cost of production is a certain constant; there is a linear demand function in the market.

Inverse linear demand function in duopoly market is assumed as follows:

$$
p(Q)=a-b Q
$$

where $Q$ is the total supply of homogeneous products in duopoly market: $Q=q_{1}+q_{2}$ and $p$ is the market price. The output of oligopolist 1 is $q_{1}$, the output of oligopolist 2 is $q_{2}$, spontaneous demand is $a$, sensitivity coefficient to price of demand is $b$. The profits of oligopolists are

$$
\pi_{i}\left(q_{i}, q_{j}\right)=p(Q) q_{i}-c_{i} q_{i}, \quad i=1,2 ; i \neq j .
$$

The marginal cost of production of two oligopolists $c_{i}>0$ meets $a>\max \left(c_{1}, c_{2}\right), b>0$. If oligopolist has the same marginal cost of production and chooses optimal output independently, then the profits of each oligopolist are

$$
\begin{aligned}
\pi_{1} & =q_{1}(p-c)=q_{1}\left(a-b\left(q_{1}+q_{2}\right)-c\right) \\
& =-b q_{1}^{2}+(a-c) q_{1}-b q_{1} q_{2}, \\
\pi_{2} & =q_{2}(p-c)=q_{2}\left(a-b\left(q_{1}+q_{2}\right)-c\right) \\
& =-b q_{2}^{2}+(a-c) q_{2}-b q_{1} q_{2} .
\end{aligned}
$$

Since oligopolists are pursuing profits maximization, first order condition is

$$
\begin{aligned}
& \frac{\partial \pi_{1}}{\partial q_{1}}=-2 b q_{1}+(a-c)-b q_{2}=0 \\
& \frac{\partial \pi_{1}}{\partial q_{2}}=-2 b q_{2}+(a-c)-b q_{1}=0 .
\end{aligned}
$$

Combine the above two equations, and we could obtain equilibrium outputs and profits of oligopolists:

$$
q_{1}=q_{2}=\frac{a-c}{3 b}, \quad \pi_{1}=\pi_{2}=\frac{(a-c)^{2}}{9 b} .
$$

Thus we could obtain Cournot equilibrium under the condition of complete information. Equilibrium outputs of oligopolists $q_{1}$ and $q_{2}$ are optimal output assumed fixed 
output of their rival, so Cournot equilibrium is a subset of Nash equilibrium.

According to market concentration $\mathrm{CR}_{2}$ and $\mathrm{CR}_{4}$ of preponderant metal mineral resources in China, these resources are monopolistic and each oligopolist according to its own profit maximization makes decision simultaneously in oligopoly market. Therefore, this paper uses Cournot game model to analyze the influence exerted on development compensation value and pricing mechanism by combinational equilibrium evaluation factors, to analyze the function routes of combinational equilibrium evaluation factors to preponderant metal mineral resources pricing power and follow the classical assumptions of Cournot equilibrium, that is, assuming oligarchs marginal production cost $c$ is equal. According to the market supply and demand situation and national industrial policy, this paper analyzes the relationship between demand and price of preponderant metal mineral resources by using regression analysis, which shows the feasibility to simulate product demand function by linear demand function in oligopoly market. Therefore, it is assumed that linear inverse demand function of metal mineral resources products is $p=a-q_{1}-q_{2}, q_{1}$ is the output of oligopolist 1 , and $q_{2}$ is the output of oligopolist 2 and satisfies the spontaneous demand of the market $a>c$, so oligarchs profits objective functions ignoring psychological preferences of players are as follows:

$$
\begin{aligned}
& f_{1}\left(q_{1}, q_{2}\right)=q_{1}\left(a-q_{1}-q_{2}\right)-c q_{1}, \\
& f_{2}\left(q_{1}, q_{2}\right)=q_{2}\left(a-q_{1}-q_{2}\right)-c q_{2},
\end{aligned}
$$

where $a$ in (6) and (7) stands for spontaneous demand of metal minerals; function $f_{1}$ and $f_{2}$ stands for profit function of oligopolists, respectively.

Combine (6) with (7), we could obtain Cournot game equilibrium of each oligopolist:

$$
\left(q_{1}, q_{2}\right)=\left(\frac{a-c}{3}, \frac{a-c}{3}\right) .
$$

\subsection{Intergenerational Compensation Modification of Prepon-} derant Metal Mineral Resources Development and Compensation. The essence of the preponderant metal mineral resources depletion compensation is value compensation to future losses aiming at excessive mining contemporarily. According to equity theory, externalities of different economic subjects could be solved through negotiations in preponderant metal mineral resources development. If there is reasonable institutional arrangements, the externalities could be internalized to a great extent. However, the externality in mineral resources development for the contemporary is better than the descendant, and because the latter is absent in game negotiation, they could not restrict behavior of the contemporary which cause asymmetry between behaviors. In order to solve the internalization of intergenerational externality problem under the condition of asymmetry, we could build the sustainable development compensation fund in the process of mineral resources development on the basis of the theory of Hotelling mineral resources depletion compensation and Howarth intergenerational property transfer theory. Sustainable development compensation fund is a cash conversion mode; if discount rate is considered, it will keep growing. If intergenerational compensation cost is $F$, time horizon for compensation is $T$, and then the intergenerational compensation fund needed is $s=F /(1+R)^{T}$ and $R$ is social discount rate.

With the development of world economy, the preponderant metal mineral resources are scarcer, and many countries are looking for a new substitute to get rid of the dependence on metal mineral resources. From the perspective of sustainable development, this research input could affect development routes and improve efficiency of preponderant metal mineral resources, to ensure the rights and interests of future generations. In consequence, research input of substitute should be regarded as part of the intergenerational development compensation value. Research input of substitute contributes to lower current consumption of metal mineral resources from the aspect of metal mineral resources recycling and extends the development and utilization period to meet the needs of metal mineral resources for both the contemporary and the descendent from the aspect of substitute researches.

\subsection{The Function Routes of Intergenerational Equity Com-} pensation to Preponderant Metal Mineral Resources Strategic Equilibrium Price. Take intergenerational equity value, that is, sustainable development of the compensation fund $s(s>$ 0 ) as intergenerational equity compensation. Metal mineral resources development and utilization cost become the combination of marginal production cost and marginal external cost, namely, $c+s$, and inverse demand function of mineral resources products in international market is $p=a-q_{1}-q_{2}$ and satisfies $a>c+s$; the objective function of each country is

$$
\begin{aligned}
& f_{1}\left(q_{1}, q_{2}\right)=q_{1}\left(a-q_{1}-q_{2}-c-s\right), \\
& f_{2}\left(q_{1}, q_{2}\right)=q_{2}\left(a-q_{1}-q_{2}-c-s\right) .
\end{aligned}
$$

Combined (9) with (10), we could obtain Cournot equilibrium from the intergenerational compensation perspective:

$$
\left(q_{1}^{*}, q_{2}^{*}\right)=\left(\frac{a-c-s}{3}, \frac{a-c-s}{3}\right) .
$$

Compare (11) to (8); it could be deduced that international trade price of preponderant metal mineral resources should be included into intergenerational compensation modification so as to show its depletion cost of metal minerals. In this way, the supply of preponderant metal mineral resources will decrease, and international trade price will increase. Besides, the greater the intergenerational equity compensation is, the higher the degree of market monopoly will be, so the initial price of metal mineral prices should be higher.

The intergenerational equity compensation of research inputs mainly considers the effects on metal mineral resources development and utilization by technical progress, which would give rise to the appearance of new substitute and affect price elasticity of demand of the replaced metal 
mineral resources products. Given impacts of substitute, the demand equation of new metal mineral resources products is $p_{t}=a^{\prime}-q_{1 t}-q_{2 t}$.

The higher the metal mineral resource price is, the more obvious the substitution will be. Then, the trigger point will appear at a rather low price, that is, $a^{\prime}<a$, reaching the new equilibrium as follows:

$$
\left(q_{1 t}^{*}, q_{2 t}^{*}\right)=\left(\frac{a^{\prime}-c}{3}, \frac{a^{\prime}-c}{3}\right) .
$$

Compare (12) to (8); we could deduce that total market output of metal mineral resource products is smaller when intergenerational compensation cost of substitutes is considered. Besides, the more the research input of substitutes is, the higher the degree of market monopoly will be, so the initial price of metal mineral prices should be higher. There is no sustainable development compensation fund established to consider intergenerational equity compensation, and no account set up for substitutes research input in accounting system, resulting in underestimation of development compensation costs and deficiency in intrinsic value compensation. In reality, the lower metal premium on mineral resources leads to lower international trade prices. And due to low entry barriers, the development of metal mineral resources exists many problems, such as, small scale, operation chaos and overexploitation, which generate excessive competition and vicious circle to further price reduction.

\section{The Function Routes of Social Preference to Preponderant Metal Mineral Resources Pricing Power}

3.1. The Utility Function Modification in Decision Making of Preponderant Metal Mineral Resources Development. Under the imperfect competition market structure, fair price reflects not only intrinsic value compensation equity, industrial organization trade forces equity, and policies trading forces equity in oligopoly market structure of preponderant metal mineral resources, but also supply and demand of intrinsic value compensation equilibrium fluctuations caused by the above equities. From the perspective of behavioral economics, the influences exerted on shadow price and profits by fair belief of stakeholders should be considered in the trade forces equity. As to measurement of strategic value and equity level, it is advisable to learn from the establishment of social utility function. For example, in strategic production decision, if a resource developer has reciprocal preference hopes that the production of its competitor is more than equity output accepted by players, the oligopolist is willing to reduce profits of competitors by squeezing its own profits; if a resource developer has reciprocal preference hopes that the production of its competitor is less than equity output accepted by players, the oligopolist is willing to increase profits of competitors by squeezing its own profits. The profits variation above is the producer surplus variation; hence, it is possible to measure strategic value produced by psychological preferences by the variation of preponderant metal mineral resources developers surplus caused by price variation. Under oligopoly market structure, the modification of psychological preferences to developer decision-making utility function should be under the condition of interdependence preferences; metal mineral resources developer output decisionmaking utility function included into psychological effects of social preferences is as follows:

$$
\begin{aligned}
U_{i}\left(O\left(s_{i}, s_{i}^{*}\right)\right)= & \pi_{i}\left(O\left(s_{i}, s_{-i}^{*}\right)\right) \\
& +\sum_{j \neq i} w_{i j}\left(s_{i}, s_{-i}^{*}\right) \pi_{j}\left(O\left(s_{i}, s_{-i}^{*}\right)\right) .
\end{aligned}
$$

In (13), where $O\left(s_{i}, s_{i}^{*}\right)$ is the output decision under interdependence strategy, $s_{i}$ is the output strategy of oligopolist $i, s_{-i}^{*}$ is the output strategy of remaining oligopolists, $\pi_{i}$ is oligopolist $i$ 's profits without considering interdependent preferences, $\pi_{j}$ is the profit of other oligopolists without considering interdependence preferences, and $w_{i j}$ is the coefficient of strategic interaction measuring the profit that oligopolist $i$ gives to other oligopolists. Positive values of the coefficient $w_{i j}$ mean that player $i$ is willing to sacrifice his payoff from outcomes in order to increase the payoff of player $j$. Negative values mean that player $i$ is willing to sacrifice his payoff from outcomes in order to lower player $j$ 's payoff. In addition, $w_{i j}\left(s_{i}, s_{-i}^{*}\right) \pi_{j}\left(O\left(s_{i}, s_{-i}^{*}\right)\right)$ can be decided by the different types of social preferences as follows.

(1) If the oligopolist prefers altruism fairness, that is, the oligopolist considers the intertemporal allocation of preponderant mental mineral resources development and the utilization of later generations, then the oligopolists have slight altruistic preferences, and $w_{i j}$ is positive.

(2) For types of inequity averse player, $w_{i j}\left(s_{i}, s_{-i}^{*}\right) \pi_{j}\left(O\left(s_{i}, s_{-i}^{*}\right)\right)$ can be replaced by $w_{i j}\left(q_{i}, Q_{-i}^{*}\right)\left(\pi_{j}-\pi_{i}\right), w_{i j}\left(q_{i}, Q_{-i}^{*}\right)$ is used to measure the deviation profit function of oligopolist $i$ puting weights on oligopolist $j$, and here is

$$
w_{i j}\left(q_{i}, Q_{-i}^{*}\right) \begin{cases}>0, & \pi_{j}<\pi_{i} \\ =0, & \pi_{j}=\pi_{i} \\ <0, & \pi_{j}>\pi_{i}\end{cases}
$$

The first condition expresses aversion to advantageous inequity, namely, if oligopolist $i$ 's profits are greater than those of oligopolist $j$, then oligopolist $i$ is willing to sacrifice its own profits to increase $j$ 's profits. The third condition expresses aversion to disadvantageous inequity. If oligopolist $i$ 's profits are lower than those of oligopolist $j$, then oligopolist $i$ is willing to sacrifice its own profits to reduce $j$ 's profits.

(3) If it is the reciprocal fairness preference, the payoff function of the oligopolist $i$ is $U_{i}\left(q_{i}, Q_{-i}\right)=$ $\pi_{i}\left(q_{i}, Q_{-i}\right)+w_{i}\left(Q_{-i}, Q_{-i}^{F}\right) \sum_{j \neq i} \pi_{i}\left(q_{i}, Q_{-i}\right)$. Where $\pi_{i}\left(q_{i}, Q_{-i}\right)$ is oligopolist $i$ 's profits and is the weight that oligopolist $i$ places on its rivals gross profits, that is, $\sum_{j \neq i} \pi_{i}\left(q_{i}, Q_{-i}\right)$, and on the gross output of its rivals $Q_{-i}$, the equation is $\pi_{i}\left(q_{i}, Q_{-i}\right)=R_{i}\left(q_{i}, Q_{-i}\right)-C_{i}\left(q_{i}\right)$, 
where $R_{i}\left(q_{i}, Q_{-i}\right)=P(Q) q_{i}$ is revenue. Assuming that oligopolist $i$ is endowed with the weight on its rivals depending on fair gross output $Q_{-i}^{F}$ and output of his rivals. Furthermore, it can be assumed that

$$
w_{i}\left(Q_{-i}, Q_{-i}^{F}\right) \begin{cases}>0, & Q_{-i}<Q_{-i}^{F} \\ =0, & Q_{-i}=Q_{-i}^{F} \\ <0, & Q_{-i}>Q_{-i}^{F}\end{cases}
$$

That is, when $Q_{-i}<Q_{-i}^{F}$ the oligopolist $i$ has a positive weight on rivals' gross profits; when $Q_{-i}=Q_{-i}^{F}$, the weight is 0 ; and it has a negative weight on its rivals' output when $Q_{-i}>Q_{-i}^{F}$. These conditions reveal the real intention of oligopolist with reciprocal fairness preference to care rivals. The Rabin fairness equilibrium determination method used by reciprocal fairness psychological compensation value modification is that game subjects are willing to sacrifice their material interests to help people who treat them kindly and to punish people who treat them badly; the smaller the sacrifice, the greater motivation to help and punish.

\subsection{The Function Routes of Social Preference to Preponderant} Metal Mineral Resources Strategic Equilibrium Price. Based on the revised developers' utility function, the developers will play strategic reciprocal game on production when exploiting preponderant mental mineral resources; meanwhile they can tell the industry is oligopoly by judging from the market concentration indicators of $\mathrm{CR}_{2}$ and $\mathrm{CR}_{4}$ of preponderant metal mineral resources. Thus, developers will play oligopolistic reciprocal fairness game, and each oligopolist based on profit maximization principle to make decision simultaneously. Therefore, the Cournot game model is fit to analyze the function routes of social preferences to preponderant metal mineral resources pricing power improvement.

3.2.1. The Function Routes of Altruism Preference to Preponderant Metal Mineral Resources Strategic Equilibrium Price. Preponderant metal mineral resources development requires sustainable development, so it could be assumed that slight altruistic preference is possessed on the consideration of intergenerational equity. According to (13) and Cournot hypothesis, monopoly profit functions under altruism preference of preponderant metal mineral resources development are

$$
\begin{aligned}
\pi_{1}\left(q_{1}, q_{2}, \lambda_{1}\right)= & q_{1}\left(a-q_{1}-q_{2}-c-s\right) \\
& +\lambda_{1} q_{2}\left(a-q_{1}-q_{2}-c-s\right), \\
\pi_{2}\left(q_{1}, q_{2}, \lambda_{2}\right)= & q_{2}\left(a-q_{1}-q_{2}-c-s\right) \\
& +\lambda_{2} q_{1}\left(a-q_{1}-q_{2}-c-s\right),
\end{aligned}
$$

where $\lambda_{i}(i=1,2)$ is oligopolist $i$ 's slight altruism preference coefficient, and $\lambda_{i} \geq 0$. Altruism preference coefficients fall in the interval $(0,1)$ approximately revealed by game experiments according behavior of experimental economics and psychology, such as trust game, gift exchange game, dictator game, and market game with punishment or without punishment. According to the optimal Cournot equilibrium analysis method, the optimal reaction function of each oligopolist could be gained from (16) and (17):

$$
\begin{aligned}
& \frac{\partial \pi_{1}}{q_{1}}=\left(a-2 q_{1}-q_{2}-c-s\right)-\lambda_{1} q_{2}=0, \\
& \frac{\partial \pi_{2}}{q_{2}}=\left(a-2 q_{2}-q_{1}-c-s\right)-\lambda_{2} q_{1}=0 .
\end{aligned}
$$

Combine (18) with (19), we could obtain Cournot equilibrium under pure altruism preference:

$$
\begin{aligned}
& \left(q_{1}^{* *}, q_{2}^{* *}\right) \\
& \quad=\left(\frac{\left(1-\lambda_{1}\right)(a-c-s)}{4-\left(1-\lambda_{1}\right)\left(1-\lambda_{2}\right)}, \frac{\left(1-\lambda_{2}\right)(a-c-s)}{4-\left(1-\lambda_{1}\right)\left(1-\lambda_{2}\right)}\right) .
\end{aligned}
$$

Using Cournot equilibrium output under altruism preference of oligopolist 1 minus that in (11), we could get the equation:

$$
\begin{aligned}
& \frac{\left(1+\lambda_{1}\right)(a-c-s)}{4-\left(1-\lambda_{1}\right)\left(1-\lambda_{2}\right)}-\frac{(a-c-s)}{3} \\
& =\frac{(a-c-s)\left(-2 \lambda_{1}-\lambda_{2}+\lambda_{1} \lambda_{2}\right)}{3\left[4-\left(1-\lambda_{1}\right)\left(1-\lambda_{2}\right)\right]} .
\end{aligned}
$$

Since $\left(\lambda_{1}, \lambda_{2}\right) \rightarrow 0,(a-c-s) / 3\left[4-\left(1-\lambda_{1}\right)\left(1-\lambda_{2}\right)\right]>0$, and $\left(-2 \lambda_{1}-\lambda_{2}+\lambda_{1} \lambda_{2}\right)<0$, the Cournot equilibrium output under pure altruism condition is lower than that under no altruism condition. And the higher the degree of altruism preference is, the smaller the total market output will be, so strategic price of preponderant metal mineral resources development and compensation should be higher.

3.2.2. The Function Routes of Inequity Aversion to Preponderant Metal Mineral Resources Strategic Equilibrium Price. In the development compensation pricing of preponderant mental mineral resources, oligopolists show sympathy preference and jealousy preference on the players' payoffs, say, they will sacrifice their profits to lower those oligopolists who obtain higher profits, but also sacrifice their profits to upgrade those oligopolists who bear lower profits. According to Fehr and Schmidt's definition of inequity aversion, the payoff functions of preponderant mental mineral resources development and utilization are affected by oligopolists' inequity aversion preferences, and thus their payoff functions are

$$
\begin{aligned}
\pi_{1}\left(q_{1}, q_{2}, \alpha_{1}, \beta_{1}\right)=f_{1}- & {\left[a_{1} \max \left(f_{2}-f_{1}, 0\right)\right.} \\
+ & \left.\beta_{1} \max \left(f_{1}-f_{2}, 0\right)\right], \\
\pi_{2}\left(q_{1}, q_{2}, \alpha_{2}, \beta_{2}\right)=f_{2}- & {\left[a_{2} \max \left(f_{1}-f_{2}, 0\right)\right.} \\
+ & \left.\beta_{1} \max \left(f_{2}-f_{1}, 0\right)\right],
\end{aligned}
$$

where $\alpha_{i}(i=1,2)$ is the jealousy preference coefficient under inequity aversion of oligopolist $i$ and $\beta_{i}(i=1,2)$ is the sympathy preference coefficient under inequity aversion; 
moreover, $\alpha_{i}>\beta_{i}>0$. And owing to the symmetry form in oligopoly market structure, the assumption of $f_{2}>f_{1}$ will not affect analysis conclusion; thus (22) are as follows:

$$
\begin{aligned}
& \pi_{1}\left(q_{1}, q_{2}, \alpha_{1}\right)= q_{1}\left(a-q_{1}-q_{2}-c-s\right) \\
&-\alpha_{1}\left[q_{2}\left(a-q_{1}-q_{2}-c-s\right)\right.\left.-q_{1}\left(a-q_{1}-q_{2}-c-s\right)\right] \\
& \pi_{2}\left(q_{1}, q_{2}, \alpha_{2}\right)= q_{2}\left(a-q_{1}-q_{2}-c-s\right) \\
&-\beta_{2}\left[q_{2}\left(a-q_{1}-q_{2}-c-s\right)\right. \\
&\left.\quad-q_{1}\left(a-q_{1}-q_{2}-c-s\right)\right],
\end{aligned}
$$

where $\alpha_{i}(i=1,2)$ is the jealousy preference coefficient under inequity aversion of oligopolist $i$ and $\beta_{i}(i=1,2)$ is the sympathy preference coefficient under inequity aversion. The second items on the right side in (23) are disutility produced by oligopolist $i$ 's jealousy preference. According to the optimal Cournot equilibrium analysis, the optimal response function of each oligopolist derived from revenue functions under inequity aversion is as follows:

$$
\begin{aligned}
& \frac{\partial \pi_{1}}{q_{1}}=\left(a-2 q_{1}-c-s\right)\left(1+\alpha_{1}\right)-q_{2}=0, \\
& \frac{\partial \pi_{2}}{q_{2}}=\left(a-2 q_{2}-c-s\right)\left(1-\beta_{2}\right)-q_{1}=0 .
\end{aligned}
$$

Combine (24) with (25); the optimal production of each oligopolist preferring inequity aversion can be finally written as

$$
\begin{aligned}
\left(q_{1}^{* * *}, q_{2}^{* * *}\right)= & \left(\frac{\left(1+2 \alpha_{1}\right)\left(1-\beta_{2}\right)(a-c-s)}{4\left(1+\alpha_{1}\right)\left(1-\beta_{2}\right)-1},\right. \\
& \left.\frac{\left(1+\alpha_{1}\right)\left(1-2 \beta_{2}\right)(a-c-s)}{4\left(1+\alpha_{1}\right)\left(1-\beta_{2}\right)-1}\right) .
\end{aligned}
$$

The fairness equilibrium output function exhibits that under piecewise linear inequity aversion condition, the optimal response function of oligopolist and standard Cournot equilibrium game are both continuous, but the former is no longer monotonous.

Using Cournot equilibrium output in (26) minus that in (11), we could get the equation:

$$
\begin{aligned}
& q_{1}^{* * *}-q_{1}^{* *}=\frac{2 a_{1}+\beta_{2}-2 a_{1} \beta_{2}}{12\left(1+\alpha_{1}\right)\left(1-\beta_{2}\right)-3}(a-c-s), \\
& q_{2}^{* * *}-q_{2}^{* *}=\frac{-a_{1}-2 \beta_{2}-2 a_{1} \beta_{2}}{12\left(1+\alpha_{1}\right)\left(1-\beta_{2}\right)-3}(a-c-s) .
\end{aligned}
$$

The result of (28) is obviously less than zero. After thousands of game experiments, such as ultimatum game, dictator game, and public good games in different countries, it proves that about $85 \%$ of the people's $\alpha_{1}$ and $\beta_{1}$ fall in the interval $(0.15,0.50)$, so the result of $(27)$ is more than zero. Equation (27) shows that Cournot equilibrium output preferring fairness is more than that when they are only concerned about their own enterprise profits, while (28) shows that Cournot equilibrium output preferring fairness is less than that when they are only concerned about their own enterprise profits. Such results indicate the effects of sympathy and jealousy preference on the Cournot equilibrium, and weak complementary between degree of oligopolist's sympathy and equilibrium output, that is, when jealousy preferences is greater, the optimal Nash equilibrium market output under inequity aversion in Cournot game will be larger. Under the circumstances, the improvement of jealousy preferences reduces the producer surplus and increases consumer surplus. On the other side, the minimal Nash equilibrium market output under piecewise linear inequity aversion in Cournot game will decrease when sympathy preferences are greater. In this case, the improvement of sympathy preferences increases the producer surplus and reduces consumer surplus. The variation of producer surplus is greater than that of consumer surplus after considering fairness preference, thus producing strategic reciprocal value for oligopolists. Therefore, it is necessary to take compensation of strategic reciprocal value in price system into account in the pricing process of preponderant metal mineral resources.

\subsubsection{The Function Routes of Reciprocal Equity Equilibrium to} Preponderant Metal Mineral Resources Strategic Equilibrium Price. Under the condition of intergenerational equity equilibrium and according to the definition of reciprocal equity equilibrium, the players' revenue function of preponderant metal mineral resources development is

$$
\begin{aligned}
\pi_{1}\left(q_{1}, q_{2}\right) & =q_{1}\left(a-q_{1}-q_{2}-c-s\right) ; \\
\pi_{2}\left(q_{1}, q_{2}\right) & =q_{2}\left(a-q_{1}-q_{2}-c-s\right) \\
\pi_{1}^{h}\left(q_{1}\right) & =q_{1}\left(a-q_{1}-c-s\right) ; \\
\pi_{1}^{e}\left(q_{1}\right) & =\frac{q_{1}\left(a-q_{1}-c-s\right)}{2} \\
\pi_{2}^{h}\left(q_{2}\right) & =q_{2}\left(a-q_{2}-c-s\right) ; \\
\pi_{1}^{e}\left(q_{2}\right) & =\frac{q_{2}\left(a-q_{2}-c-s\right)}{2},
\end{aligned}
$$

where $\pi_{1}^{l}\left(q_{1}\right)=0, \pi_{1}^{\min }\left(q_{1}\right)=0, \pi_{2}^{l}\left(q_{2}\right)=0, \pi_{2}^{\min }\left(q_{2}\right)=0$. According to the definition of reciprocal equity equilibrium, in the transaction of preponderant metal mineral resources, the friendliness function between oligopolist 1 and oligopolist 2 is

$$
\begin{aligned}
& f_{1}\left(q_{1}, q_{2}\right)=\frac{1}{2}-\frac{q_{1}}{a-q_{2}-c-s}, \\
& f_{2}\left(q_{1}, q_{2}\right)=\frac{1}{2}-\frac{q_{2}}{a-q_{1}-c-s} .
\end{aligned}
$$


Friendliness belief between oligopolist 1 and oligopolist 2 is

$$
\begin{aligned}
& \tilde{f}_{2}\left(\widetilde{q}_{1}, q_{2}\right)=\frac{1}{2}-\frac{q_{2}}{a-\tilde{q}_{1}-c-s}, \\
& \tilde{f}_{1}\left(q_{1}, \widetilde{q}_{2}\right)=\frac{1}{2}-\frac{q_{1}}{a-\tilde{q}_{2}-c-s} .
\end{aligned}
$$

According to the definition of (29) and (33), the utility functions of different players in preponderant metal mineral resources development are

$$
\begin{aligned}
U_{1}\left(q_{1}, q_{2}, \tilde{q}_{1}\right)= & \pi_{1}\left(q_{1}, q_{2}\right)+\tilde{f}_{2}\left(\tilde{q}_{1}, q_{2}\right)+\left[1+f_{1}\left(q_{1}, q_{2}\right)\right] \\
= & q_{1}\left(a-q_{1}-q_{2}-c-s\right) \\
& +\left[\frac{1}{2}-\frac{q_{2}}{a-\tilde{q}_{1}-c-s}\right] \\
& \times\left[\frac{3}{2}-\frac{q_{1}}{a-q_{2}-c-s}\right] \\
U_{1}\left(q_{1}, q_{2}, \tilde{q}_{1}\right)= & \pi_{2}\left(q_{1}, q_{2}\right)+\tilde{f}_{1}\left(q_{1}, \tilde{q}_{2}\right)\left[1+f_{1}\left(q_{1}, q_{2}\right)\right] \\
= & q_{2}\left(a-q_{1}-q_{2}-c-s\right) \\
& +\left[\frac{1}{2}-\frac{q_{1}}{a-\tilde{q}_{2}-c-s}\right] \\
& \times\left[\frac{3}{2}-\frac{q_{2}}{a-q_{1}-c-s}\right]
\end{aligned}
$$

Combine (34) with (35) to get the first-order optimal solution, thus obtaining Cournot equilibrium solution under reciprocal equity equilibrium:

$$
\begin{aligned}
& q_{1}^{* * * *}=\frac{1}{2}\left(\frac{4 a-4 c-4 s}{3}-\frac{\sqrt{3+(a-c-s)^{2}}}{3}\right. \\
& \left.-\frac{2(a c+a s) \sqrt{3+(a-c-s)^{2}}}{9}\right) \\
& +\frac{1}{2}\left(\frac{(c+s)^{2} \sqrt{3+(a-c-s)^{2}}}{9}\right. \\
& +\frac{a^{2} \sqrt{3+(a-c-s)^{2}}}{9} \\
& \left.-\frac{\left[3+(a-c-s)^{2}\right]^{3 / 2}}{9}\right) \\
& q_{2}^{* * * *}=\frac{1}{3}\left(2 a-2 c-2 s-\sqrt{3+(a-c-s)^{2}}\right) .
\end{aligned}
$$

It could be seen in (30) that $q_{2}^{* * * *}<(1 / 3)(2 a-2 c-2 s-$ $\left.\sqrt{(a-c-s)^{2}}\right)=(a-c-s) / 3=q_{2}^{* *}$; similarly, $q_{1}^{* * * *}<q_{1}^{* *}$. It suggests that after considering reciprocal equity preferences, the total market output of preponderant metal mineral resources is reduced and the degree of market monopoly is higher. The demand price elasticity of preponderant metal mineral resources is rather small for the reason that they are industrial raw materials and hard to be replaced. Given reciprocal equity equilibrium, the market capacity is decreased and then caused higher prices. The greater producer surplus is strategic reciprocal value produced by reciprocal equity preference, which should be included in compensation value system. If oligopolist 1 and oligopolist 2 are present two countries, it is observed that two countries having reciprocal equity intention could enhance their metal mineral resources market monopoly status, thereby obtaining pricing power for themselves. It also explains the reason why China should obey reciprocal equality principles in international trade.

\section{Simulation Analysis}

As has been observed from (20), (26), and (36), oligarchs' social preferences in preponderant metal market, that is, altruism preference, inequity aversion, and reciprocal fairness, produce psychological effects, which raise the power of oligarch market and change output decision (reducing production) of each oligarch by being blend in decision function. Therefore, market capacity is decreased and price of supply and demand is increased. Considering the significance of preponderant metals, their demand is rigid, so developers has larger producer surplus, which is strategic reciprocal value produced by reciprocal fairness. However, it can be seen from equilibrium results of the above four equations that forms of strategic value are various. So the method of numerical simulation is used to verify as follows.

4.1. Original Basic Parameter Setting. According to the market supply and demand of lithium, antimony, indium, rare earth, and the national industrial policy as well as the regression analysis of the Cournot linear demand function, the spontaneous demand stabilized at around 2,000 tons, so $a$ in the Cournot model can take the value 2000, namely, $a=2000$, by analyzing the tax subjects of preponderant mental mineral resources development, namely, the property cost (mineral resources compensation, resource tax), mining costs (outlay of exploration, outlay of mining), investment capital (capital investment per ton of mineral resources), production costs (raw materials, power costs, wages and benefits, manufacturing costs, processing fees, finance charges, and operating expenses), security costs (safety training, disinfection equipment, risk assessment costs, occupational funds, and pension), and part of the measurable environmental governance operating costs (water pollution, air pollution, waste pollution, and heavy metal pollution), and environmental restoration costs (mine land reclamation bond, tailings management costs, and mine environmental geology warning inputs). Based on tax subjects above and the statistical analysis of preponderant 

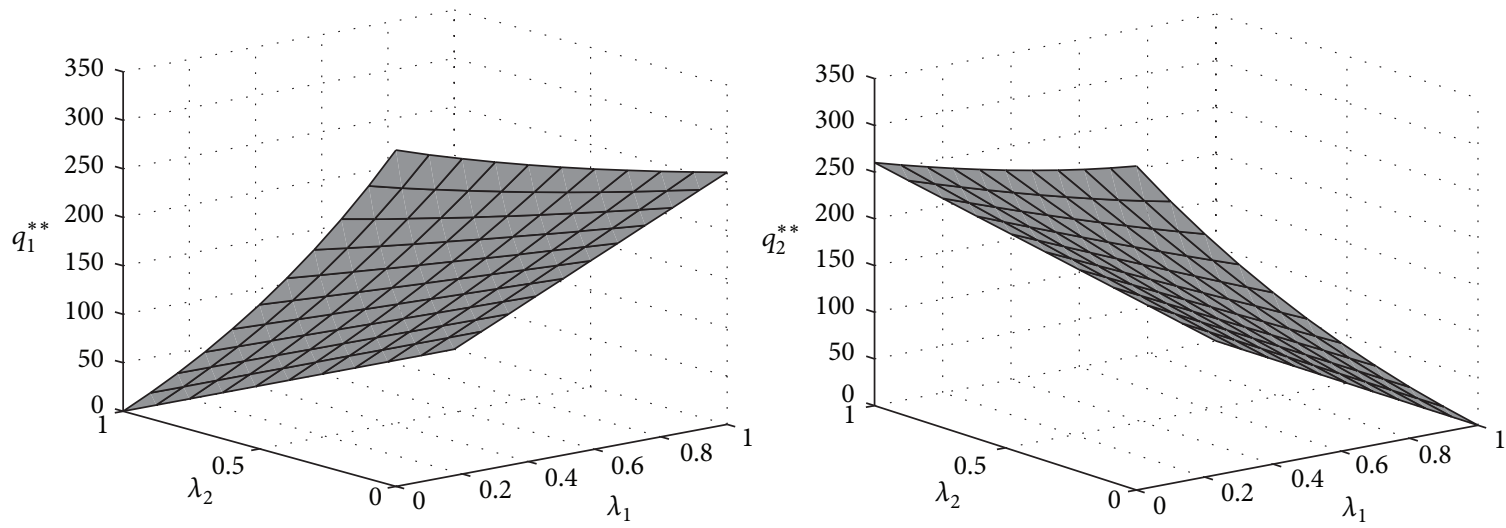

FIGURE 1: The sensitivity analysis of Cournot equilibrium output to altruism preference coefficient.

metal development compensation enterprises, the basic cost $c$ of preponderant mental mineral resources development compensation enterprises is about 800 units; original basic parameter setting in Section 4.1 is obtained by regression estimation in last 10 years, so it conforms to the market situation. Thus the results of numerical simulation could support the application of practical program. The sustainable development fund is used to measure modification of intergenerational compensation, estimates depletion costs of rare earth, lithium, and indium by modified user cost approach and gains the proportion of depletion cost to total cost is $20 \%$. The depletion cost is the reflection of intergenerational compensation modification actually, so the value of sustainable development fund $s$ of intergeneration equity is 160 units.

\subsection{Impacts Exerted on Cournot Equilibrium by Coefficients} of Altruism Preference and Inequity Aversion. Reciprocal equity Cournot equilibrium variation under reciprocal equity preference has the consistent results with classic Cournot equilibrium, so numerical simulation is not needed to analyze its character. However, Cournot equilibrium under social preferences produces a new equilibrium bringing about a new character, on account of the variation of altruism preferences and the loss aversion of inequity aversion; thus, numerical simulation is required. Altruism preference coefficients fall in the interval $(0,1)$ revealed by game experiments and modified game experiments of altruism preference and inequity aversion preference, such as, ultimatum game, dictator game, public good games, gift exchange game, and third-party punishment game. While the distribution of inequity aversion coefficients has the following features, as is shown in Table 1.

4.2.1. Simulation Results of Impact Exerted on Cournot Equilibrium by Altruism Preference. Altruism preference coefficients could be obtained by game experiments and impacts exerted on Cournot equilibrium decision-making by altruism preference could be simulated by (20) and (21). The specific content is shown in Figure 1.
As can be seen from Figure 1, the Cournot equilibrium output under altruism preference modified by intergenerational equity is changing as follows. In a certain condition, the altruism degree of oligopolist 2 is in proportion to that of oligopolist 1, namely, the bigger the altruism coefficient of oligopolist 2 is, the smaller the Cournot equilibrium output of oligopolist 1 is, and vice versa. This result is in accordance with the experiment result of pure altruism preference. According to Cournot equilibrium and analysis framework of supply and demand, the reduction of Cournot equilibrium output will raise price in preponderant mental market, while to those preponderant mental resources lacking price elasticity of demand, price increase will lead to producer surplus increase, which is the strategic value of development and compensation of preponderant metal resources.

4.2.2. Simulation Results of Impact Exerted on Cournot Equilibrium by Inequity Aversion. Inequity aversion coefficients could be obtained by game experiments and impacts exerted on Cournot equilibrium decision-making by inequity aversion which could be simulated by (26) and (28). The specific content is shown in Figure 2.

As can be seen from Figure 2, Cournot equilibrium output under intergenerational equity correction when inequity aversion is considered is smaller than that when they are not considered. The oligopolists under inequity aversion lift the degree of market monopoly of preponderant metal mineral resources. Besides, the higher the degree of jealousy preference is, the larger the Cournot equilibrium output will be, while as to sympathy preference, the result is completely opposite. These results are consistent with the results of theoretical model; namely, Cournot equilibrium under inequity aversion has the character of loss aversion.

\section{Conclusions}

This paper analyzes the modification of intergenerational equity and social preferences to fiducial value of preponderant metal mineral resources and qualifies the impacts exerted on Cournot equilibrium by interdependence preferences 

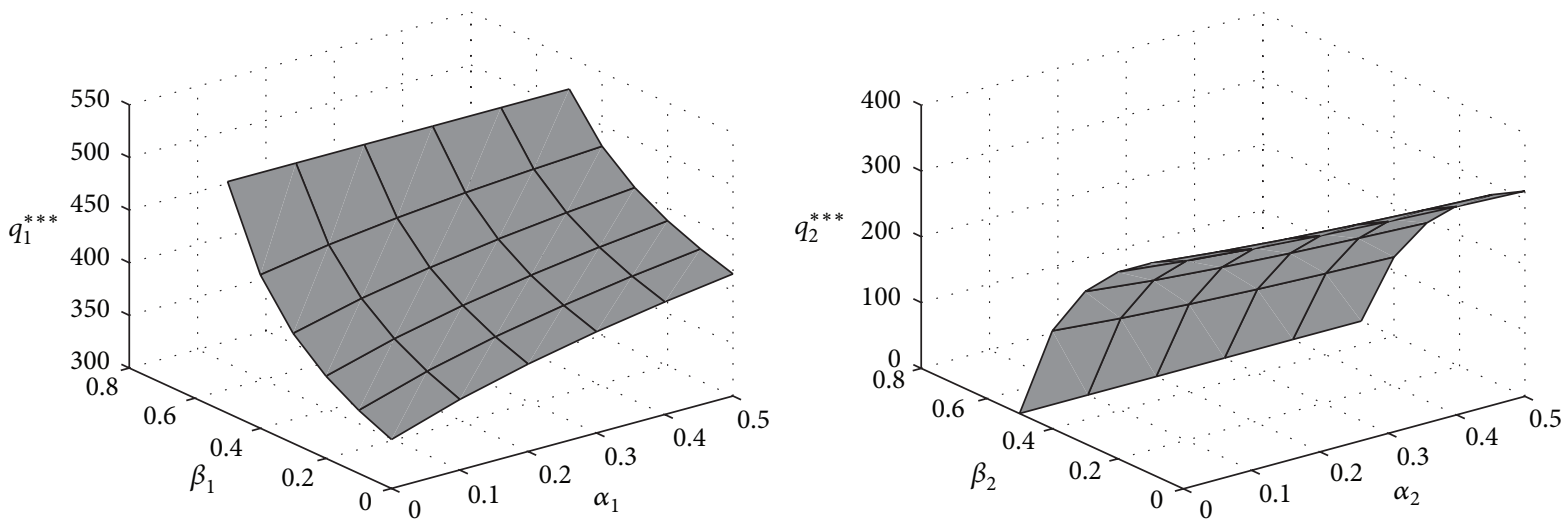

FIGURE 2: The sensitivity analysis of Cournot equilibrium output to inequity aversion preference.

TABLE 1: The distribution of jealousy and sympathy preferences coefficients $\alpha$ and $\beta$ under inequity aversion.

\begin{tabular}{lccc}
\hline & Value and proportion of $\alpha$ & \multicolumn{2}{c}{ Value and proportion of $\beta$} \\
Value of $\alpha$ & Proportion (\%) & Value of $\beta$ & Proportion (\%) \\
\hline$\alpha=0$ & 20 & $\beta=0$ & 30 \\
$\alpha=0.5$ & 65 & $\beta=0.25$ & 45 \\
$\alpha=1$ & 10 & $\beta=0.6$ & 10 \\
$\alpha=4$ & 5 & 5 \\
\hline
\end{tabular}

(altruism preference, inequity aversion, and reciprocal equity preference), thus drawing the following conclusions.

(1) Considering the intergenerational equity and social preferences in preponderant metal mineral resources development, Cournot equilibrium market capacity becomes smaller. Because preponderant metal mineral resources are significant to national security and industrial development and hard to replace, the demand of those prices is rigid. Therefore, when Cournot equilibrium decreases, oligopolist's profits increase; that is, oligopolist's producer surplus increases. The variation of producer surplus is intergenerational equity compensation value and strategic value when intergenerational equity and social preferences blend into Cournot game.

(2) However, the impact exerted on Cournot market power by social preferences is inconsistent. Variation of altruism Cournot equilibrium and reciprocal equity Cournot equilibrium are consistent, while Cournot equilibrium under inequity aversion has the characteristic of loss aversion, namely, under the consideration of inequity aversion Cournot competition, Cournot Nash equilibrium transform monotonically with sympathy and jealousy inequity aversion; that is, if the jealousy degree of oligopoly increased, Cournot Nash equilibrium is near the perfect competition output equilibrium; if the sympathy degree of oligopoly increased, Cournot Nash equilibrium is near the optimal collusion equilibrium output.

The results indicate that the essence of price distortion of preponderant metal mineral resources is incomplete value realization and resource value compensation inequity, failing to realize the goal of mineral resources price reform, namely, two basic conditions for the reform are not satisfied. The production value of mineral resources is achieved through spontaneous effect of the market for its relevance to efficiency. However, the property value, intragenerational value, and intergenerational value of mineral resources are difficult to realize spontaneously on account of their public characteristic under market effect. It is difficult for marketoriented reform of mineral resources price to fully realize the mineral resources value and provide a fundamental guarantee for sufficient and reasonable compensation. Therefore, to achieve the goal of mineral resources price reform, it is necessary to reconstruct value compensation system of metal mineral resources development. According to redefinition of preponderant metal mineral resources development under the principle of multiple equilibrium value evaluation, the actual negotiated pricing mechanism is classified based on mineral resources pricing mechanism of multiple equilibrium evaluation models; that is, pricing should fully reflect the complete elements of mineral resources and coordinate interests between players. As to practical operation scheme of current resources tax reform, value measurement of preponderant metal mineral resources development compensation should analyze from not only development and utilization results but also the perspective of strategic reciprocal psychology. Besides, the value system of preponderant metal mineral resources development compensation contains economic value and ecological value as well as strategic value. Furthermore, since social preferences are added into the value system of preponderant metal mineral resources development compensation, the market monopoly degree 
will be strengthened and development compensation price will be higher, which require perfect tax subjects and establish full cost theory system, thus estimating mineral resources value correctly and making the international trade fair prices tend to rationalization.

\section{Conflict of Interests}

The authors declare that there is no conflict of interests regarding the publication of this paper.

\section{Acknowledgment}

This work was partially supported by the National Natural Science Foundation of China (71171203, 71073177), the major Project of National Social Science Foundation (13\&ZD024, 13\&ZD169), the Research Project in Humanities and Social Sciences of Chinese Ministry of Education (13YJAZH149, 09YJC90261), the Ph.D. Programs Foundation of Ministry of Education of China (20130162110076), the Emergency Project of Chinese Ministry of Education (2009 JYJR035), the China Postdoctoral Science Foundation (20110491264), the Special Project of Postdoctoral Research Funds of Hunan Province (S2011R1040), and the Project of Soft Science of Hunan Province (2009ZK3193).

\section{References}

[1] J. T. Hu, "Hold high the great banner of socialism with Chinese characteristics and strive for new victories in building a moderately prosperous society in all respects," in Proceedings of the 17th National Congress of the Communist Party of China, Beijing, China, 2007.

[2] J. T. Hu, "Firmly march on the path of socialism with Chinese characteristics and strive to complete the building of a moderately prosperous society in all respects," in Proceedings of the 18th National Congress of the Communist Party of China, Beijing, China, 2012.

[3] H. Hotelling, "The economics of exhaustible resources," Journal of Political Economy, vol. 39, no. 2, pp. 137-175, 1931.

[4] J. M. Hartwick, "Intergenerational equity and the investing of rents from exhaustible resources," The American Economic Review, vol. 67, no. 5, pp. 972-974, 1977.

[5] E. Serafy, "Absorptive capacity, the demand for revenue, and the supply of petroleum," The Journal of Energy and Development, vol. 7, no. 1, pp. 73-88, 1981.

[6] E. Serafy, "The proper calculation of income from depletable natural resources," in Environmental Accouting for Sustainable Development, a UNEP-World Bank Sympoisum, Y. J. Ahmed, S. E. Seral, and E. Lutz, Eds., The World Bank, Washington, DC, USA, 1989.

[7] M. A. Adelman, "User cost in oil production," Resources and Energy, vol. 13, no. 3, pp. 217-240, 1991.

[8] C. E. F. Young and R. Seroa Da Motta, "Measuring sustainable income from mineral extraction in Brazil," Resources Policy, vol. 21, no. 2, pp. 113-125, 1995.

[9] J. N. Blignaut and R. M. Hassan, "Assessment of the performance and sustainability of mining sub-soil assets for economic development in South Africa," Ecological Economics, vol. 40, no. 1, pp. 89-101, 2002.
[10] B. Q. Lin, X. Y. Liu, C. Y. Zou, and X. Liu, "Resource tax reform: a case study of coal from the perspective of resource economics," Social Sciences in China, vol. 18, no. 3, pp. 116-139, 2012.

[11] G. P. Li and H. W. Li, "The perfection of user cost approach and the estimation of user cost of oil and gas resources of America," Journal of Natural Resources, vol. 28, no. 6, pp. 1046-1058, 2013.

[12] X. F. Zeng and G. P. Li, "A new estimation of user costs for nonrenewable energy resources," Resources Science, vol. 35, no. 2, pp. 439-446, 2013.

[13] B. Fattouh, OPEC Pricing Power: The Need for a New Perspective, vol. 158, Oxford University Press, 2007.

[14] R. K. Kaufmann, "The mechanisms for autonomous energy efficiency increases: a cointegration analysis of the US energy/GDP ratio," The Energy Journal, vol. 25, no. 1, pp. 63-86, 2004.

[15] A. Rubinstein, "Perfect equilibrium in a bargaining model," Econometrica, vol. 50, no. 1, pp. 97-109, 1982.

[16] F. Wen, X. Gong, Y. Chao, and X. Chen, "The effects of prior outcomes on risky choice evidence from the stock market," Mathematical Problems in Engineering, vol. 2014, Article ID 272518, 8 pages, 2014.

[17] F. Wen and X. Yang, "Skewness of return distribution and coefficient of risk premium," Journal of Systems Science \& Complexity, vol. 22, no. 3, pp. 360-371, 2009.

[18] F. Wen, Z. He, and X. Chen, "Investors' risk preference characteristics and conditional skewness," Mathematical Problems in Engineering, vol. 2014, Article ID 814965, 14 pages, 2014.

[19] F. Wen, Z. He, X. Gong, and A. Liu, "Investors' risk preference characteristics based on different reference point," Discrete Dynamics in Nature and Society, vol. 2014, Article ID 158386, 9 pages, 2014.

[20] J. Zhang, "The problem of rare earth products export pricing power loss and reason analysis," Northern Economy, no. 7, pp. 66-67, 2010.

[21] Z. M. Wang and X. J. Zhang, "Research into the effect of rare earth resource tax on the export market power of "oligarch" country," Economic Survey, no. 2, pp. 52-55, 2012.

[22] C. F. Wu and S. Jiang, "The efficiency of china's futures market: a study based on overreaction and domestic and international markets linkage," Journal of Financial Research, vol. 2, pp. 49-62, 2007.

[23] M. Rabin, "Incorporating fairness into game theory and economics," The American Economic Review, vol. 83, no. 5, pp. 12811302, 1993.

[24] M. Dufwenberg and G. Kirchsteiger, "A theory of sequential reciprocity," Discussion Paper, Tilburg University, 1998.

[25] E. Fehr and K. M. Schmidt, "A theory of fairness, competition, and cooperation," Quarterly Journal of Economics, vol. 114, no. 3, pp. 817-868, 1999.

[26] G. E. Bolton and A. Ockenfels, "ERC: a theory of equity, reciprocity, and competition," The American Economic Review, vol. 90, no. 1, pp. 166-193, 2000.

[27] M. R. Zhong, J. Y. Chen, X.-h. Zhu, and J.-b. Huang, "Strategic equilibrium price analysis and numerical simulation of preponderant high-tech metal mineral resources," Transactions of Nonferrous Metals Society of China, vol. 23, no. 10, pp. 3153-3160, 2013. 


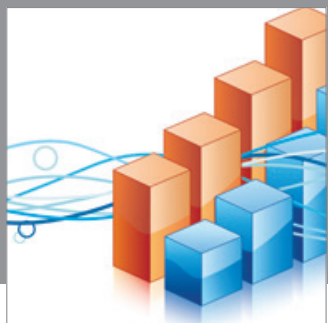

Advances in

Operations Research

mansans

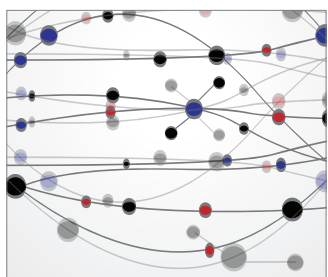

The Scientific World Journal
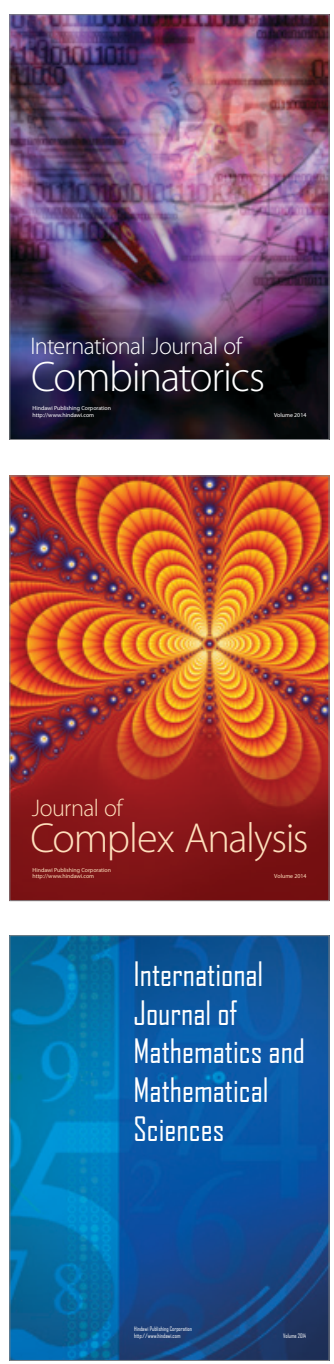
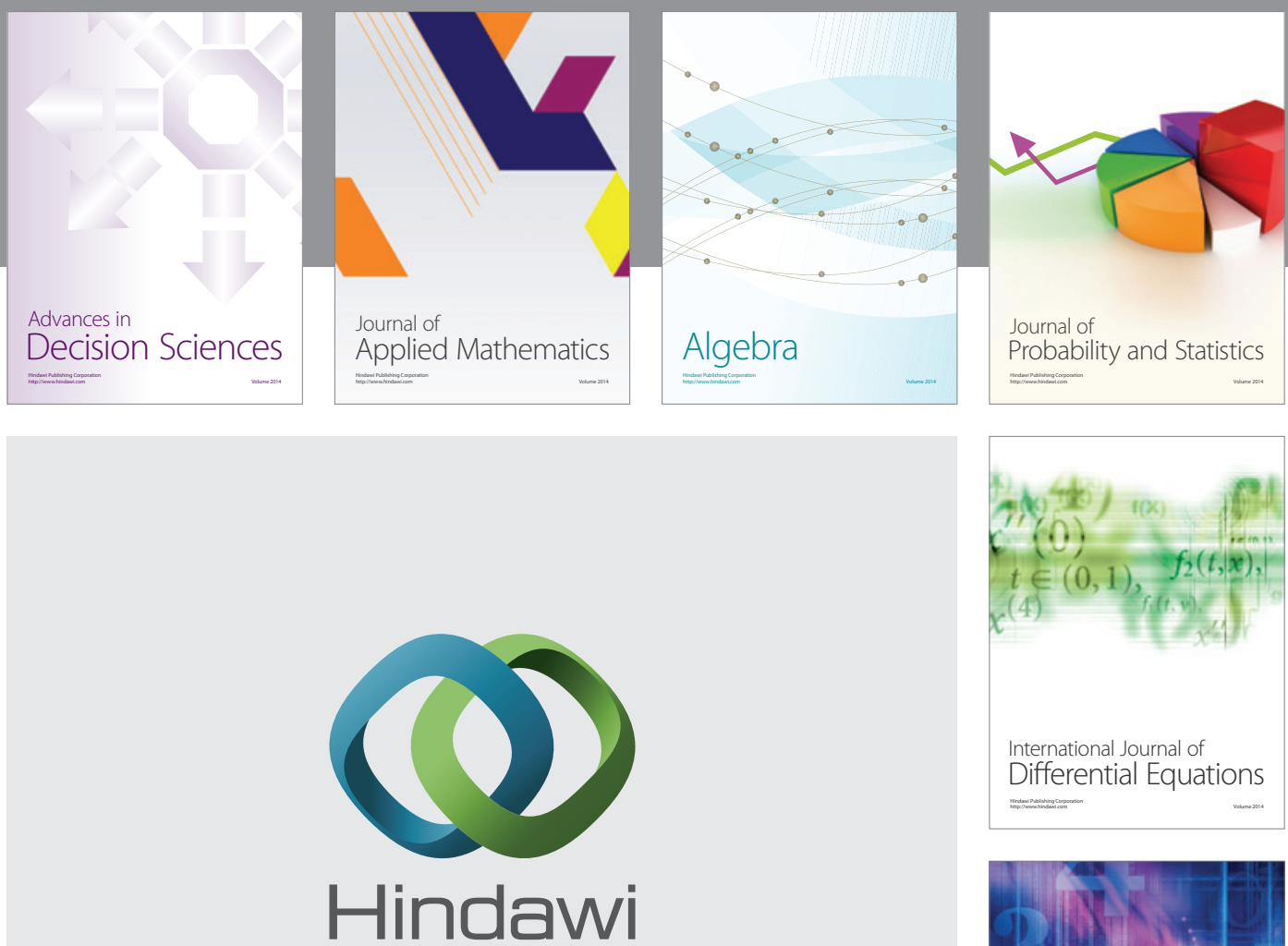

Submit your manuscripts at http://www.hindawi.com
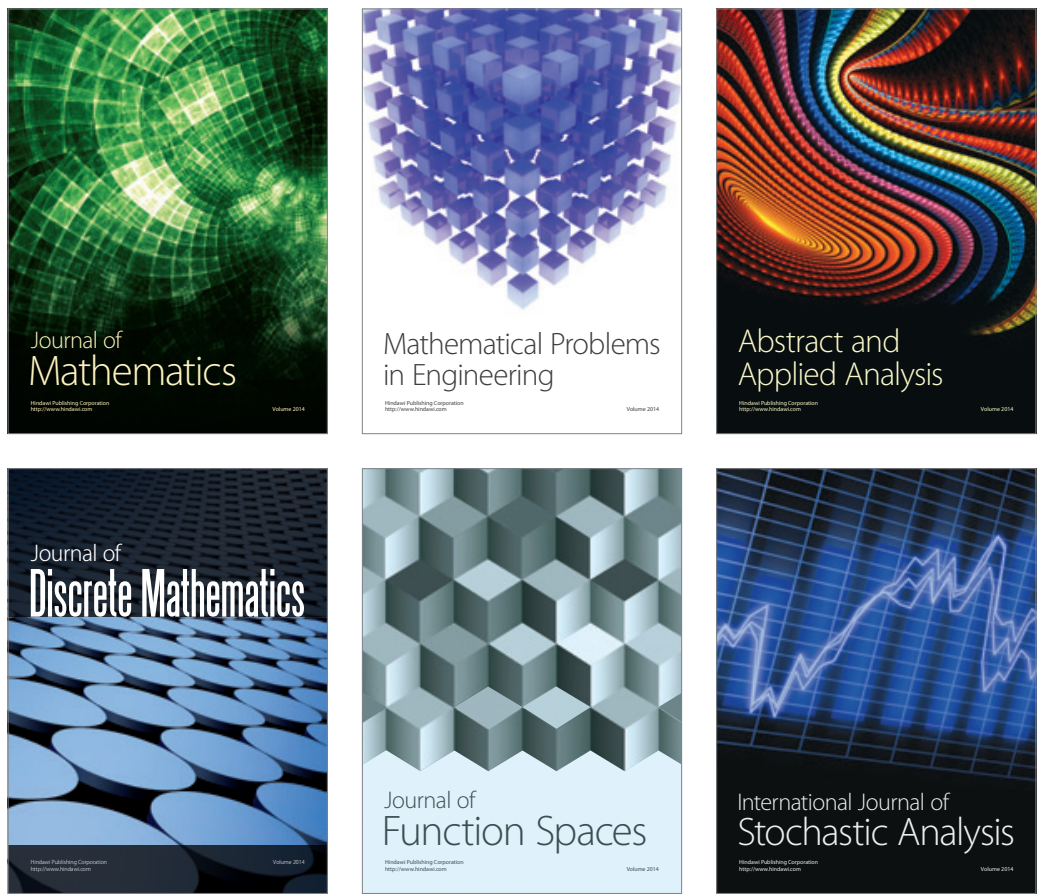

Journal of

Function Spaces

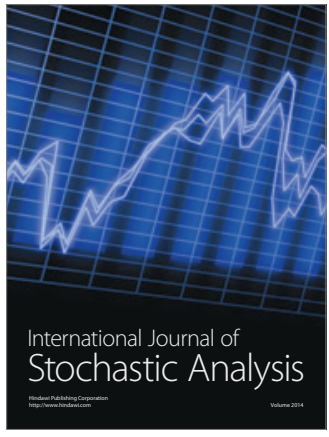

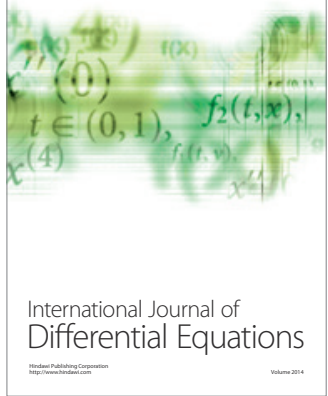
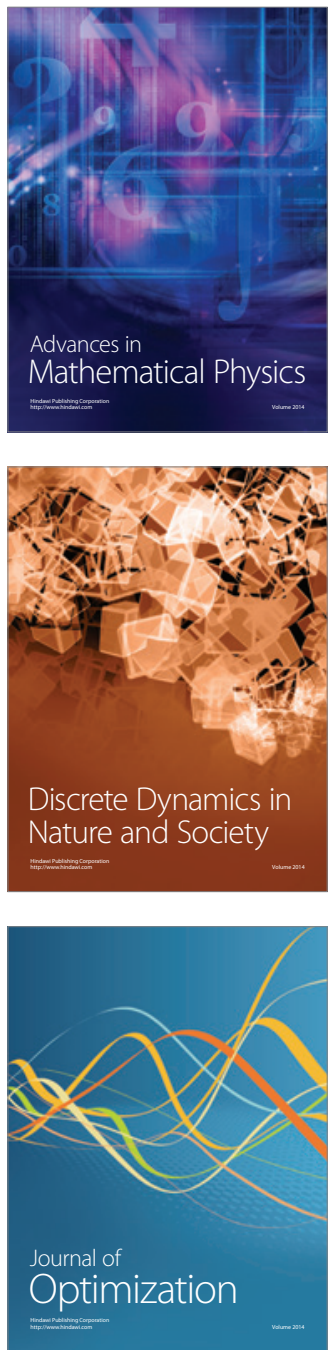